Family Profile No. 8, 2021

\title{
Same-Sex Married and Cohabiting Couples Raising Children
}

Authors: Wendy D. Manning and Krista K. Payne

A critical role of American families is to support and raise children. This profile provides the most up-to-date evidence about the share of couples raising children, disaggregating across different-sex and same-sex couples as well as across marriage and cohabitation. Since 2015, the U.S. has ensured marriage equality by guaranteeing all couples the same legal right to marry. The U.S. Census Bureau has kept pace with these changes in marriage and modified the household roster in the 2019 American Community Survey (ACS) to directly identify same-sex couples. See ABOUT THE DATA on the next page for details on how couple household data are collected in the ACS and how they are defined in this Profile. We present a single year snapshot of the share of couples who are raising a child under age 18.

The estimates of the percentage of couples raising children varied according to the couple's marital status as well as the sex composition of the couple. This highlights the importance of distinguishing between not only female and male same-sex couples, but also their relationship status to understand the family life of same-sex couples. These findings showcase the potentially important role of marriage for same-sex couples with children.

Figure 1. Presence of Biological, Adopted, Step or Foster Children of the Householder Under Age 18 Among Coupled Households by Couple Type, 2019

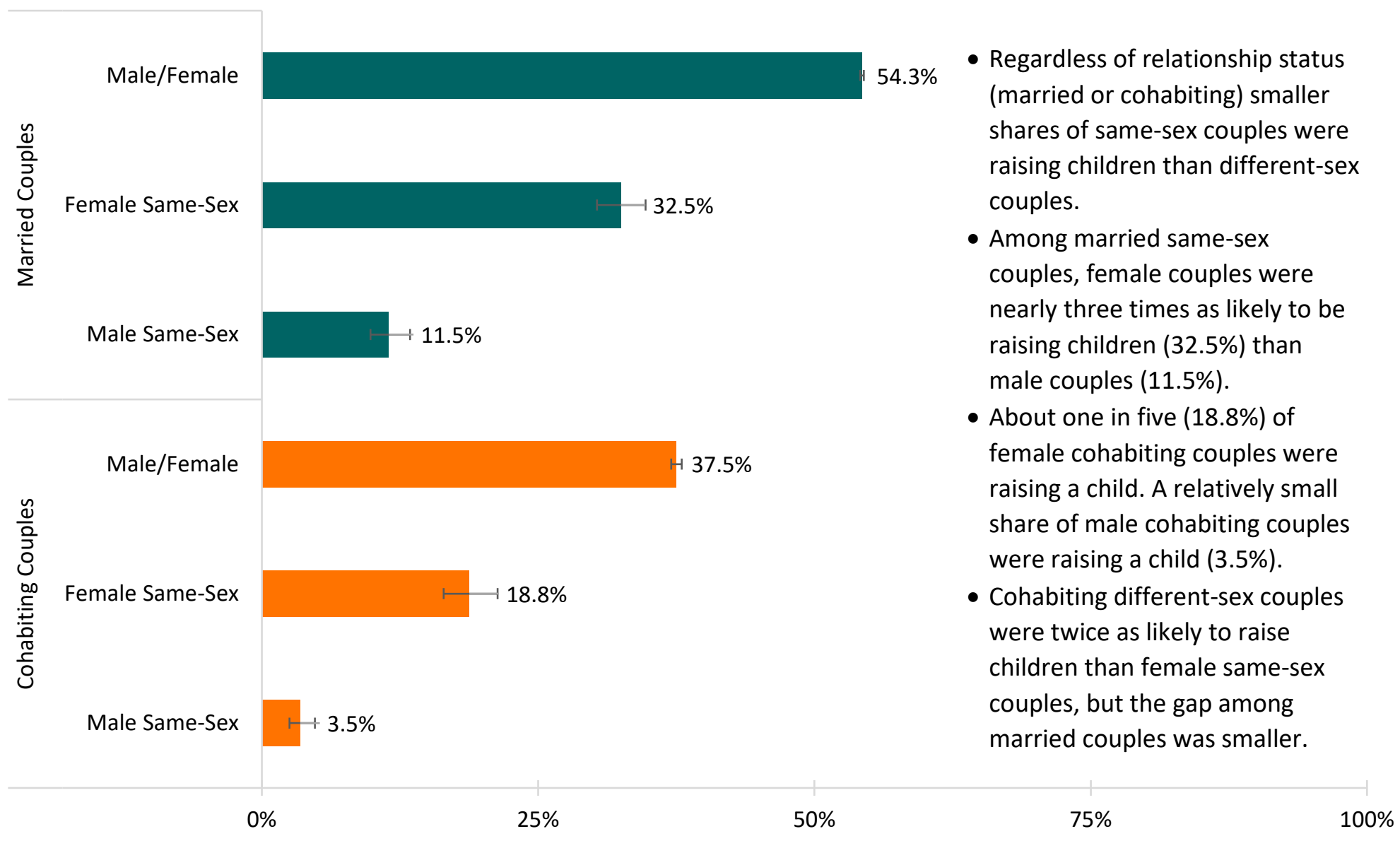

Source: NCFMR analyses of American Community Survey 1-year estimates - Public Use Microdata Sample, 2019 Note: Youngest member of the couple is under the age of 60 


\section{ABOUT THE DATA}

The recently released 2019 ACS includes the largest available nationally representative sample in the U.S. using a new household roster. The new roster directly identifies four couple relationship categories in the following order:

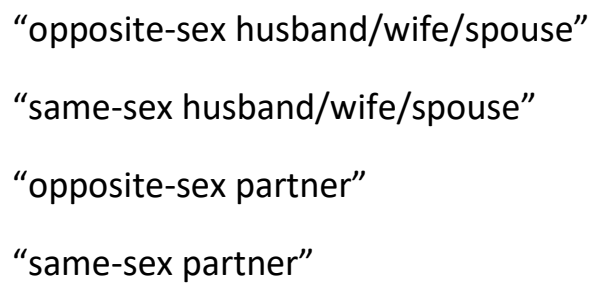

In this profile, we use the same terminology, sex rather than gender, as was used in the survey. Based on their responses, we classified couples into the following six categories:

male/female married couples

female married couples

male married couples

male/female cohabiting couples

female cohabiting couples

male cohabiting couples

Couples were coded as raising a child if the roster indicated the householder was living with a biological, adopted, step, or foster child under the age of 18. Focusing on couples in their prime ages for raising children, the sample was limited to couples with a member under age 60. The results were weighted following the ACS guidelines, and we present confidence intervals in the Figure.

\section{Suggested Citation:}

Manning, W. D. \& Payne, K. K. (2021). Same-sex married and cohabiting couples raising children. Family Profiles, FP-21-08. Bowling Green, OH: National Center for Family \& Marriage Research. https://doi.org/10.25035/ncfmr/fp-21-08 